\title{
Optimal Cut-Off Value for Homeostasis Model Assessment (HOMA) Index of Insulin- Resistance in a Population of Patients Admitted Electively in a Portuguese Cardiology
}

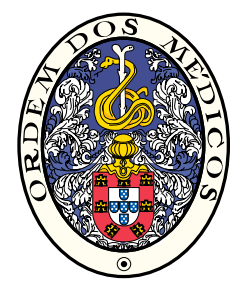

\section{Ward}

\author{
Limiar do Índice Homeostasis Model Assessment (HOMA) para Resistência à \\ Insulina numa População de Doentes Admitidos Electivamente numa \\ Enfermaria Portuguesa de Cardiologia
}

Ana Teresa TIMÓTEO ${ }^{1}$, Fernando MIRANDA ${ }^{2}$, Miguel Mota CARMO ${ }^{1}$, Rui Cruz FERREIRA ${ }^{1}$

Acta Med Port 2014 Jul-Aug;27(4):473-479

\section{ABSTRACT}

Introduction: Insulin resistance is the pathophysiological key to explain metabolic syndrome. Although clearly useful, the Homeostasis Model Assessment index (an insulin resistance measurement) hasn't been systematically applied in clinical practice. One of the main reasons is the discrepancy in cut-off values reported in different populations. We sought to evaluate in a Portuguese population the ideal cut-off for Homeostasis Model Assessment index and assess its relationship with metabolic syndrome.

Material and Methods: We selected a cohort of individuals admitted electively in a Cardiology ward with a BMI $<25 \mathrm{Kg} / \mathrm{m}^{2}$ and no abnormalities in glucose metabolism (fasting plasma glucose $<100 \mathrm{mg} / \mathrm{dL}$ and no diabetes). The 90th percentile of the Homeostasis Model Assessment index distribution was used to obtain the ideal cut-off for insulin resistance. We also selected a validation cohort of 300 individuals (no exclusion criteria applied).

Results: From 7000 individuals, and after the exclusion criteria, there were left 1784 individuals. The 90th percentile for Homeostasis Model Assessment index was 2.33. In the validation cohort, applying that cut-off, we have $49.3 \%$ of individuals with insulin resistance. However, only $69.9 \%$ of the metabolic syndrome patients had insulin resistance according to that cut-off. By ROC curve analysis, the ideal cut-off for metabolic syndrome is 2.41. Homeostasis Model Assessment index correlated with BMI $(r=0.371, p<0.001)$ and is an independent predictor of the presence of metabolic syndrome (OR 19.4, 95\% Cl $6.6-57.2, p<0.001)$.

Discussion: Our study showed that in a Portuguese population of patients admitted electively in a Cardiology ward, 2.33 is the Homeostasis Model Assessment index cut-off for insulin resistance and 2.41 for metabolic syndrome.

Conclusion: Homeostasis Model Assessment index is directly correlated with BMI and is an independent predictor of metabolic syndrome.

Keywords: Glucose Tolerance Test; Homeostasis; Insulin Resistance Metabolic Syndrome.

\section{RESUMO}

Introdução: A resistência à insulina é a chave fisiopatológica de explicação da Síndrome Metabólica. Apesar de claramente útil, o índice Homeostasis Model Assessment (uma medição da resistência à insulina) não tem sido aplicado sistematicamente na prática clínica. Uma das principais razões relaciona-se com a discrepância de valores limiares reportados em diferentes populações. Procurámos avaliar uma população portuguesa o valor limiar ideal e avaliar a sua relação com a Síndrome Metabólica.

Material e Métodos: Selecionámos uma coorte de indivíduos admitidos eletivamente numa enfermaria de cardiologia com um IMC $<25 \mathrm{Kg} / \mathrm{m}^{2}$ e sem anomalias do metabolismo da glicose (glicémia em jejum < $100 \mathrm{mg} / \mathrm{dL}$ e sem diabetes). Utilizámos o percentil 90 da distribuição do índice Homeostasis Model Assessment para seleção do limiar adequado para resistência à insulina. Selecionouse também uma coorte de validação composta por 300 indivíduos, sem aplicação dos critérios de exclusão referidos anteriormente.

Resultados: De uma população de 7000 indivíduos e após aplicação dos critérios de exclusão, ficámos com 1784 indivíduos para análise. O percentil 90 do índice foi 2,33. Na coorte de validação, aplicando esse limiar, $49,3 \%$ dos indivíduos apresentam resistência à insulina. Contudo, apenas $69,9 \%$ dos doentes com síndrome metabólica apresentam resistência à insulina com esse limiar. Por análise das curvas ROC, o limiar ideal para síndrome metabólica é 2,41. O índice Homeostasis Model Assessment correlacionou-se com o IMC $(r=0,371, p<0,001)$ e é um preditor independente de presença de síndrome metabólica (OR 19,4, IC 95\% 6,6 - 57,2, $p<0,001)$.

Discussão: O nosso estudo mostrou que numa população portuguesa de doentes admitidos eletivamente numa enfermaria de cardiologia, o limiar pelo índice Homeostasis Model Assessment para resistência à insulina é 2,33 e para síndrome metabólica é 2,41.

Conclusão: $O$ índice Homeostasis Model Assessment correlacionou-se com o IMC e é um preditor independente de síndrome metabólica.

Palavras-chave: Teste de Tolerância a Glicose; Homeostase; Resistência à Insulina; Síndrome Metabólica; Doenças Cardiovasculares.

\section{INTRODUCTION}

Cardiovascular diseases are the leading cause of death in developed countries, including Portugal, not only as far

as ischemic heart disease is concerned, but particularly in terms of stroke, the incidence of which is among the high-

1. Serviço de Cardiologia. Hospital de Santa Marta. Centro Hospitalar Lisboa Central. Lisboa. Portugal.

2. Serviço de Patologia Clínica. Hospital de Santa Marta. Centro Hospitalar Lisboa Central. Lisboa. Portugal.

Recebido: 16 de Janeiro de 2014 - Aceite: 01 de Julho de 2014 | Copyright @ Ordem dos Médicos 2014 
est in the world. ${ }^{1}$ In fact, in developed countries, the most common cardiovascular disease is ischemic heart disease, which is also the leading cause of death in all European Union with the exception of Greece, the former Yugoslavia Republic of Macedonia and Portugal, where it is stroke. ${ }^{2}$ Clinically it is of great significance the identification of patients at risk of developing cardiovascular events to enable preventive interventions and to promote life style changes.

Overweight and obesity have risen dramatically in developed countries, resulting in a marked increase in metabolic syndrome, a clustering of cardiovascular risk factors including central adiposity, hypertension, dyslipidemia, and a proinflammatory state, conferring risk of atherosclerotic cardiovascular disease. Traditional risk prediction scores have proven very useful in identifying persons at risk for coronary heart disease, but such tools have limitations. Metabolic syndrome is one of such risk factors, but not included in the most common risk scores. Insulin resistance is the cornerstone of metabolic syndrome and a simple measurement can be used to detect it. ${ }^{3}$ The standard technique for assessment of insulin sensitivity is the hyperinsulinemic euglycemic clamp. ${ }^{4}$ However, although clamp technology has been applied to the study of insulin sensitivity and insulin secretion, it is time consuming and difficult to apply in clinical practice. Several non-invasive measurement techniques have been proposed, such as the fasting glucose / insulin ratio (FGIR), quantitative insulin sensitivity check index (QUICKI) and the Homeostasis Model Assessment (HOMA) index and each correlated reasonably well with clamp techniques. ${ }^{5-9}$ The HOMA approach, introduced by Matthews et al has been widely used in clinical research to assess insulin sensitivity. ${ }^{7,10-13}$ However in clinical practice it is underused and the best cut-off is debated. Previous studies showed significant differences in insulin levels in different countries including European countries. ${ }^{14}$ This might have some impact in HOMA index reference levels and it calls for regional studies. In a literature review, no study was found in Portugal, where lower levels of insulin were previously reported.

In the present study, we aimed to determine insulin and HOMA index levels in a population of patients admitted electively in a Cardiology ward. We also sought to determine the ideal cut-off for insulin resistance and metabolic syndrome.

\section{MATERIAL AND METHODS}

The present study is an observational and cross-sectional study, with prospective inclusion of patients admitted for an elective cardiac procedure (coronary angiography / angioplasty, electrophysiological study / ablation, atrial septal defect / patent foramen ovale percutaneous closure, pacemaker / cardiac defibrillator / cardiac resynchronization therapy device implantation, or other procedure) between 2005 and 2011. All patients had an age $\geq 18$ years. The local institutional ethics committee approved the study and all patients gave their written informed consent.
Anthropometrical data were obtained after a 12-hour fast, with the subject in light clothing and barefoot. Body weight was measured to the nearest kilogram using a digital scale, and height to the nearest centimetre in the standing position. Body Mass Index (BMI) was calculated as weight in kilograms divided by the height in meters, squared. Waist circumference (WC) was measured to the nearest centimetre, with the subject standing, using a flexible and non-distensible tape, midway between the lower limit of the rib cage and the iliac crest.

Blood pressure was measured on several occasions during hospital stay and hypertension was defined by a previous diagnosis of hypertension, use of specific medication or the presence of systolic blood pressure $\geq$ $140 \mathrm{mmHg}$ or diastolic blood pressure $\geq 90 \mathrm{mmHg}$ (mean of three consecutive measurements). Patients that smoked during the previous six months were classified as smokers and were self-reported.

A venous blood sample was drawn after a 12-hour overnight fast. All the samples were analysed at the central laboratory of the hospital. Total cholesterol and triglycerides were determined using automatic standard routine enzymatic methods. HDL-cholesterol was determined after specific precipitation. LDL-cholesterol was determined by Friedwald formula. Blood glucose was analysed with the glucoseoxidase method (intra-assay coefficient of variation: $2.0 \%$ ). Blood insulin was analysed by electrochemilumenescence - ECLIA (intra-assay coefficient of variation: 3.5\%). The assays used were the same throughout the study. The Homeostasis Model Assessment (HOMA) index was calculated by the following equation: fasting blood glucose $(\mathrm{mg} / \mathrm{dL}) \times$ fasting blood insulin $(\mathrm{mcU} / \mathrm{mL}) / 405 .{ }^{7}$

Metabolic syndrome was defined by the most recent definition from the American Heart Association / National Heart, Lung and Blood Institute (AHA/NHLBI) in which patients had to fulfil $\geq 3$ of the following criteria: fasting glucose $\geq 100 \mathrm{mg} / \mathrm{dL}$ or specific medication; blood pressure $\geq 130 / 85 \mathrm{mmHg}$ or specific medication; triglycerides $\geq 150$ $\mathrm{mg} / \mathrm{dL}$ or specific treatment for this lipid abnormality; HDLcholesterol $<50 \mathrm{mg} / \mathrm{dL}$ in women and $<40 \mathrm{mg} / \mathrm{dL}$ in men or specific treatment for this lipid abnormality; $W C \geq 88 \mathrm{~cm}$ in women and $\geq 102 \mathrm{~cm}$ in men. ${ }^{15}$ Diabetes was recorded by the investigator based in patient history, increased glucose (fasting level $\geq 126 \mathrm{mg} / \mathrm{dL}$ ), or concomitant use of specific therapies. Patients did not stop their usual medication, except for the specific medication for diabetes which was suspended 24-48 hours before admission.

From a sample of 7000 consecutive patients, we excluded patients with a $\mathrm{BMI} \geq 25 \mathrm{Kg} / \mathrm{m}^{2}$ (overweight or obese) or with abnormal glucose regulation (AGR): diabetics or with an impaired fasting glucose (blood glucose $\geq 100$ $\mathrm{mg} / \mathrm{dL}$ ). The cut-off for insulin resistance was obtained from this selected cohort.

We used another cohort of 300 patients (included in a specific doctoral research conducted between 2008 and 2011) and not included in the previous group of patients, as a validation cohort of the obtained cut-off. This validation 
cohort included individuals similar to the previous 7000 patients sample, but the exclusion criteria were not applied. Informed consent has been obtained from each patient included in the study after explanation of the purpose and nature of all procedures used. Investigation was approved by the local ethical committee.

\section{Statistical analysis}

Statistical analysis was conducted using the PASW 18.0 statistical package (SPSS Inc, IL, Chicago, USA). A p-value $<0.05$ was considered statistically significant.

Quantitative variables were described as mean and standard deviation, or as median values and corresponding $25^{\text {th }}$ and $75^{\text {th }}$ percentiles for non-normally distributed variables and qualitative variables as percentages. Mann-Whitney's U-test or Kruskal-Wallis test were used, as appropriate, for between-.groups comparisons of continuous variables while chi-square test was used for between-group comparisons of categorical variables. Pearson's correlation was done between continuous variables. Simple and multiple logistic regression analysis were performed to determine if HOMA index is an independent predictor of metabolic syndrome.

The cut-off value for insulin resistance was based on the $90^{\text {th }}$ percentile in the selected study cohort (non-obese and without abnormal glucose regulation). For metabolic syndrome, a receiver-operating characteristic (ROC) curve was generated from the validation cohort. The area under the ROC curve (AUC) was calculated to evaluate the predictive value of HOMA index for metabolic syndrome and to determine its best cut-off. The optimal cut-off value was denoted by the value that had the largest sum of sensitivity and specificity, and, at the same time, sensitivity and specificity $\geq 60 \%$.

\section{RESULTS}

From the initial 7000 patients analysed, 5110 (73\%) were initially excluded due to overweight or obesity and another 206 patients were excluded due to diabetes or impaired fasting glucose. The final study cohort included 1784 individuals. The validation cohort included 300 patients (55.3\% with metabolic syndrome). Characteristics of both cohorts are described in Table 1. Patients in the selected study cohort were younger, less frequently males, with fewer risk factors for coronary disease and with a better metabolic profile (except for total and LDL-cholesterol). This was expected since this group has non-obese and without AGR patients. Both fasting plasma insulin (FPI) and HOMA index (Fig. 1) have a skewed distribution. FPI ranged from 0.2 to 68.7 and HOMA index ranged from 0.03 to 16.62 .

Plasma blood glucose increased significantly with age until the age of 60 years, after which it remains stable. The same was observed for FPI and HOMA index, with a slight decrease in the very aged group (Table 2). According to gender, females had lower blood glucose and high FPI. However, HOMA index was not significantly different (Table 2). There is a very significant and progressive increase of both FPI and HOMA according to BMI increase $(p<0.001)$ (Table 3). We also found a significant correlation between BMI and FPI $(r=0.389, p<0.001)$ as well as with HOMA index $(r=0.371, p<0.001)$. HOMA index is significantly higher in patients with metabolic syndrome [3.14 (2.01 - 5.05) vs. 1.67 (1.05 - 2.28), $p<0.001$ ], confirming the close association between insulin resistance and metabolic syndrome. Even in the non-diabetic group, this difference was significant [2.97 (1.80 - 6.46) vs. $1.49(0.89-2.06)$, $p<0.001$ ]

The ideal HOMA index cut-off for insulin resistance obtained from the selected study cohort is 2.33 . In the

Table 1 - Characteristics of the study population and by gender

\begin{tabular}{|c|c|c|c|}
\hline Characteristics & $\begin{array}{c}\text { Validation cohort } \\
\qquad n=300\end{array}$ & $\begin{array}{c}\text { Study cohort } \\
n=1784\end{array}$ & $p$-value \\
\hline Age (years) & $64.4 \pm 9.2$ & $58.1 \pm 18.2$ & 0.020 \\
\hline Male gender $(\%)$ & 59 & 51 & 0.012 \\
\hline \multicolumn{4}{|l|}{ Risk factors (\%) } \\
\hline Hypertension & 79 & 62 & $<0.001$ \\
\hline Hyperlipidemia & 70 & 52 & $<0.001$ \\
\hline Smoking & 9 & 14 & 0.023 \\
\hline Diabetes mellitus & 23 & 0 & $<0.001$ \\
\hline \multicolumn{4}{|l|}{ Laboratorial data } \\
\hline Glucose (mg/dL) & $100(92-115)$ & $86(79-92)$ & $<0.001$ \\
\hline Total cholesterol (mg/dL) & $181(155-213)$ & $184(156-212)$ & 0.989 \\
\hline HDL-cholesterol (mg/dL) & $43(36-54)$ & $51(42-61)$ & 0.002 \\
\hline LDL-cholesterol (mg/dL) & $114(93-136)$ & $117(96-141)$ & 0.565 \\
\hline Triglycerides (mg/dL) & $97(68-134)$ & $81(60-115)$ & 0.006 \\
\hline Insulin $(\mathrm{mcU} / \mathrm{mL})$ & $8.6(5.7-13.6)$ & $5.0(3.3-7.4)$ & $<0.001$ \\
\hline HOMA index & $2.3(1.4-3.8)$ & $1.1(0.6-1.6)$ & $<0.001$ \\
\hline
\end{tabular}




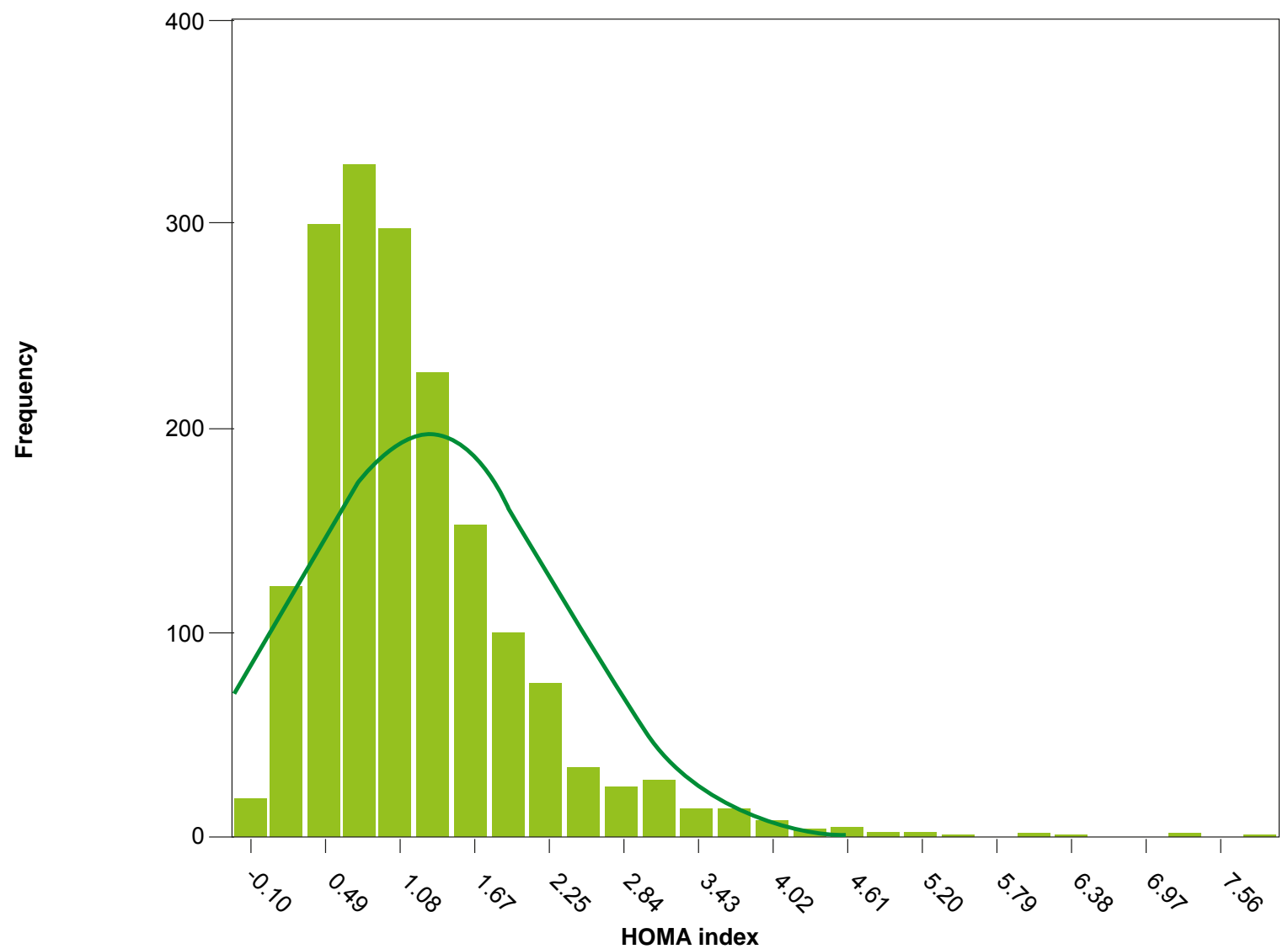

Figure 1 - Distribution of HOMA index values in the study cohort

Table 2 - Blood glucose, insulin and HOMA index according to age group and gender in the entire baseline study cohort (before exclusion criteria were applied; $n=7000$ )

\begin{tabular}{lccc}
\hline & $\begin{array}{c}\text { Glucose } \\
(\mathrm{mg} / \mathrm{dL})\end{array}$ & $\begin{array}{c}\text { Insulin } \\
(\mathrm{mcU} / \mathrm{mL})\end{array}$ & HOMA index \\
\hline$<40$ years $(n=845)$ & $82(76-89)$ & $6.0(3,7-9.3)$ & $1.2(0.7-2.0)$ \\
$40-49$ years $(n=709)$ & $86(79-92)$ & $6.0(3.9-9.6)$ & $1.2(0.7-2.0)$ \\
$50-59$ years $(n=1260)$ & $89(83-94)$ & $6.7(4.2-10.0)$ & $1.4(0.8-2.2)$ \\
$60-69$ years $(n=1725)$ & $89(83-94)$ & $6.4(4.0-9.8)$ & $1.4(0.8-2.2)$ \\
$\geq 70$ years $(n=2461)$ & $89(83-94)$ & $6.1(4.1-9.1)$ & $1.3(0.9-2.0)$ \\
$\quad p$-value & $<0.001$ & 0.043 & 0.001 \\
Males $(n=3892)$ & $89(82-94)$ & $6.1(3.9-9.5)$ & $1.3(0.8-2.1)$ \\
Females $(n=3108)$ & $87(80-93)$ & $6.4(4.2-9.5)$ & $1.4(0.8-2.1)$ \\
$\quad p$-value & $<0.001$ & 0.047 & 0.265 \\
\hline
\end{tabular}

validation cohort, using that cut-off, we have $49.3 \%$ of individuals with insulin resistance. However, only $69.9 \%$ of the patients with metabolic syndrome have insulin resistance and $23.9 \%$ of the patients without metabolic syndrome have insulin resistance $(p<0.001)$. Also, only $78.4 \%$ of the individuals with insulin resistance have metabolic syndrome.

By ROC curve analysis in the validation cohort, the HOMA index cut-off for metabolic syndrome is 2.41 , with good discriminative performance (AUC $0.78,95 \% \mathrm{Cl} 0.73$ $-0.83, p<0,001$, sensitivity $68.7 \%$, specificity $79.5 \%)$. In a multivariate regression analysis, HOMA index (adjusted for age, gender and BMI) is an independent predictor of the presence of metabolic syndrome (OR 19.4, 95\% Cl 6.6 $57.2, p<0.001)$.

\section{DISCUSSION}

Previous studies showed some discrepancies in insulin levels amongst different countries worldwide and even in European countries. In fact, the European Fat Distribution Study (EFDS), conducted in European countries, in individuals with similar age and gender, showed significant 
Table 3 - Insulin and HOMA index according to BMI group in the baseline study cohort

\begin{tabular}{lcc}
\hline & $\begin{array}{c}\text { Insulin } \\
(\mathrm{mcU} / \mathrm{mL})\end{array}$ & HOMA index \\
\hline Normal $(n=1890)$ & $6.4(4.2-9.7)$ & $1.6(0.9-2.6)$ \\
Overweight $(n=3300)$ & $8.1(5.5-11.5)$ & $2.3(1.2-3.4)$ \\
Obese $(n=1810)$ & $13.4(7.7-21.8)$ & $3.6(2.3-5.9)$ \\
\hline
\end{tabular}

differences in FPI concentrations among different European countries: the lowest value was found in Italy and Portugal and the highest in Sweden and The Netherlands. ${ }^{14}$ This difference was explained by diet and genetic factors. These results support the need for regional studies, since results cannot be generalized for all countries. For that reason, we decided to conduct a study on that subject in a Portuguese population.

HOMA index is a surrogate index widely used to study the role of insulin sensitivity / resistance in association with disease states. However, reported values for the definition of insulin resistance vary widely. Also the cut-off points to diagnose insulin resistance cannot be readily applied to all populations and may vary from race to race. ${ }^{16}$ In the literature, several cut-off values of HOMA index for insulin resistance obtained from population studies in non-obese subjects with no metabolic disorders have been suggested based on different measures of dispersion. The better method is still in debate.

Several methods have been used: $75^{\text {th }}$ percentile, $90^{\text {th }}$ percentile, lower boundary of the top quintile or tertile and others. Some authors also used ROC curves for cut-off estimation. Using the $75^{\text {th }}$ percentile, it was reported a cutoff of 1.81 in Japanese middle-aged man, 1.8 in individuals from Iran, and higher values in Spain (2.51) and China (2.67 in females and 2.48 in males). ${ }^{16-19}$ Most authors use the $90^{\text {th }}$ percentile. With that methodology, our cut-off is 2.33. This is slightly lower that the values described in Argentineans (2.64), Brazilians (2.7), Italians (2.77), and North Americans (2.7), and higher than Japanese (1.8). ${ }^{20-24}$ In a Spanish population the cut-off obtained was significantly higher (3.8). ${ }^{10}$ Inclusion and exclusion criteria were somewhat different between studies. In our study cohort, we only excluded patients with overweight / obesity and AGR. Other studies were more restrictive and also excluded patients with hypertension and lipid changes. Since our population of patients were admitted in a cardiology ward due to heart disease, these risk factors are extremely common. If these patients were excluded, our sample would be much smaller and less reliable. However, we do not think that hypertension or lipid abnormalities would have a major impact in glucose and insulin metabolism. Genetic background might be an important explanation for the different cut-points obtained. The cut-off for metabolic syndrome is similar (2.41) and the predictiveness of HOMA index for metabolic syndrome was similar to other authors. ${ }^{21}$

We confirmed an increase in HOMA index up to 60 years with subsequent stabilization. There was however a strong relationship with BMI. Other authors showed a significant age trend for HOMA index. ${ }^{25,26}$ A particular study in a Spanish population showed an increase in blood glucose, FPI and HOMA with increasing age, as in our study. ${ }^{18}$ However, this increase was explained by a higher prevalence of obesity and AGR that are known to increase with age. In fact, body composition changes, particularly in body fat distribution, which may contribute to the impairment in glucose metabolism occurring with aging. In the Spanish study, in non-obese subjects without AGR, HOMA index levels were not modified with age. ${ }^{18}$ In our study, BMI was highly correlated with HOMA index, with similar results as those obtained in the European Fat Distribution study. ${ }^{14}$ There was also no gender difference in HOMA index, as previously described by other authors.

Pathophysiologicaly, insulin resistance is the key to metabolic syndrome. ${ }^{3}$ In fact, it is described a close relationship of HOMA index and all the components of metabolic syndrome. . $^{327-30}$ This is an established index and used in most epidemiological studies. However in clinical practice it is rarely used. As in other studies, patients with metabolic syndrome have a HOMA index significantly higher, even after the exclusion of diabetic patients. ${ }^{12}$ However only $69.9 \%$ of the patients with metabolic syndrome have insulin resistance. This result is similar to other authors and challenges once again insulin resistance as the sole pathophysiological mechanism for metabolic syndrome as some authors claim.

Patients with cardiovascular disease are usually heavily medicated with some drugs that might have some implications in glucose regulation. The proportion of individuals on statin therapy was $38 \%$ in the selected study cohort and $59 \%$ in the validation cohort. Although statin therapy is widely used and safe, conflicting data exist regarding the effects of some statins on the risk of incident type 2 diabetes. A meta-analysis of 13 statin trials showed an increase in the risk for diabetes over four years that might be dose related. ${ }^{31,32}$ However, none of the trials were designed to look for incident diabetes. Further studies are therefore required to fully understand this effect. Mechanisms explaining the potential higher incidence of diabetes with statin therapy have not yet been identified. The effect on glycaemic control were deemed to be unrelated to lipid profile. ${ }^{33}$ In our selected study cohort, we found an association between statin therapy and HOMA index (linear regression, $\beta=0.076, p<0.001$ ), even after adjustment for BMI $(\beta=0.054, p=0.024)$. This has some implications in our results, because they can only be applied in similar populations. But in general practice, the proportion of patients on statin therapy is close to the one found in our study group.

Our study has other limitations that should be mentioned. This is a single centre study and the results might not be translated to the general population. However, patients' characteristics are similar to the patients followed by general practitioners. 
The absolute values of both the FPI and the HOMA index depend on the test characteristics of the insulin assay, and so the absolute values of FPI and HOMA measurements in the present study may differ from values obtained with other insulin assays.

There are two computational methods for HOMA assessment. One uses the original HOMA model formula and the other is an online calculator computer model. A study showed that the two methods have different cut-offs for the definition of insulin resistance (2.5 and 1.4, respectively) and the first has higher association with metabolic syndrome. ${ }^{34}$ Our study used the manual calculation, so it does not apply to online calculator computed values.

Stress might influence blood glucose and FPI. All patients were admitted for a cardiac procedure, with some stress associated. However, since HOMA index is a ratio that includes both insulin and glucose, this effect might be minimized. Also, simple procedures such as blood drawing, as in the case for the euglycemic clamp technique (a standard technique to evaluate insulin resistance) can cause some stress for patients and this is considered acceptable for the measurement of insulin resistance.

\section{CONCLUSION}

Our study showed that in a Portuguese population of patients admitted electively in a Cardiology ward, 2.33 is the HOMA index cut-off for insulin resistance and 2.41 for metabolic syndrome. HOMA index is directly correlated with $\mathrm{BMI}$ and is an independent predictor of metabolic syndrome.

\section{CONFLICTS OF INTEREST}

The authors declare that there are no conflicts of interest.

\section{FUNDING SOURCES}

No subsidies or grants contributed to this work.

\section{REFERENCES}

1. The European Health Report 2009. Health and Health Systems. Copenhagen: World Health Organization Regional Office for Europe; 2009.

2. World Health Organization on behalf of the European Observatory of Health Systems and Policies. Health in the European Union. Trends and analysis. Copenhagen: World Health Organization Regional Office for Europe; 2009.

3. Sealy $\mathrm{CH}$, Aczel S, Marte T, Langer P, Hoefle G, Drexel H. The metabolic syndrome, insulin resistance, and cardiovascular risk in diabetic and nondiabetic patients. J Clin Endocrinol Metab. 2005;90:5698-703.

4. Haymond MW. Measuring insulin resistance: a task worth doing. But how? Pediatr Diabetes. 2003;4:115-8.

5. Silfen ME, Manibo AM, McMahon DJ, Levine LS, Murphy AR, Oberfield SE. Comparison of simple measures of insulin sensitivity in young girls with premature adrenarch: the fasting glucose to insulin ratio may be a simple and useful measure. J Clin Endocrinol Metab. 2001;86:2863-8.

6. Quon MJ. Limitations of the fasting glucose to insulin ratio as an index of insulin sensitivity. J Clin Endocrinol Metab. 2001;85:4615-7.

7. Matthews DR, Hosker JP, Rudenski AS, Naylor BA, Treacher DF, Turner RC. Homeostasis model assessment: insulin resistance and B-cell function from fasting plasma glucose and insulin concentrations in man. Diabetologia. 1985;28:412-9.

8. Laakso M. How good marker is insulin level for insulin resistance? Am J Epidemiol. 1993;137:959-65.

9. Wallace TM, Matthews DR. The assessment of insulin resistance in man. Diabetic Med. 2002;19:527-34.

10. Ascaso JF, Romero P, Real JT, Priego A, Valdecabres C, Carmena R. Insulin resistance quantification by fasting insulin plasma values and HOMA index in a non-diabetic population. Med Clin. 2001;117:530-3.

11. Reilly MP, Wolfe ML, Rhodes T, Girman C, Mehta N, Rader DJ. Measures of insulin resistance add incremental value to the clinical diagnosis of metabolic syndrome in association with coronary atherosclerosis. Circulation. 2004;110:803-9.

12. Vonbank A, Sealy $\mathrm{CH}$, Rein P, Beer S, Breuss J, Boehnel C, et al. Insulin resistance is associated with the metabolic syndrome and is not directly linked to coronary artery disease. Clin Chim Acta. 2011;12:1003-7.

13. Bravata DM, Wells CK, Concato J, Kernan WN, Brass LM, Gulanski BI. Two measures of insulin sensivity provided similar information in a U.S. population. J Clin Epidemiol. 2004;57:1214-7.

14. Cigolini M, Seidell J, Targher G, De Slypere JP, Ellsinger BM, Charzewska J, et al. Fasting serum insulin in relation to components of the metabolic syndrome in European healthy men: The European Fat Distribution Study. Metabolism. 1995;44:35-40.

15. Grundy SM, Cleeman JI, Daniels SR, Donato KA, Eckle RH, Franklin $\mathrm{BA}$, et al. Diagnosis and management of the metabolic syndrome. An American Heart Association/National Heart, Lung, and Blood Institute Scientific Statement. Circulation. 2005;112:2735-52.

16. Esteghamati A, Ashraf $H$, Esteghamati AR, Meysamie A, Khalilzadeh $O$, Nakhjavani $M$, et al. Optimal threshold of homeostasis model assessment for insulin resistance in an Iranian population: The implications of metabolic syndrome to detect insulin resistance. Diabet Res Clin Pract. 2009;84:279-87.

17. Otake T, Fukumoto J, Abe M, Takemura S, Minn PN, Mizoue T, et al. Linking lifestyle factors and insulin resistance, based on fasting plasma insulin and HOMA-IR in middle-aged Japanese men: a cross-sectional study. Scan J Clin Lab Invest. 2014 (in press).

18. Soriguer F, Colomo N, Valdés S, Goday A, Rubio-Martín E, Esteva I, et al. Modifications of the homeostasis model assessment of insulin resistance index with age. Acta Diabetol. 2014 (in press).

19. Sun Y, Li W, Hou X, Wang C, Li C, Zhang X, et al. Triglyceride and ratio of triglycerides to high-density lipoprotein cholesterol are better than liver enzymes to identify insulin resistance in urban middle-aged and older non-obese Chinese without diabetes. Chin Med J. 2014;127:185862.

20. Buccini GS, Wolfthal DL. Valores de corte para índices de insulinorresistencia, insulinosensibilidad e insulinosecreción derivados de la fórmula HOMA y del programa HOMA2. Interpretación de los datos. Rev Arg Endocrinol Metab. 2008;45:3-21.

21. Geloneze B, Vasques ACJ, Stabe CFC, Pareja JC, Rosado LE, Queiroz $E C$, et al. HOMA1-IR and HOMA2-IR indexes in identifying insulin resistance and metabolic syndrome. Brazilian Metabolic Syndrome Study (BRAMS). Arq Bras Endocrinol Metab. 2009;53:281-7.

22. Bonora E, Kiechl S, Willeit J, Oberhollenzer F, Egger G, Targher G, et al. Prevalence of insulin resistance in metabolic disorders: the Bruneck Study. Diabetes. 1998;47:1643-9.

23. Yeni-Komshian H, Caratoni M, Abbasi F, Reaven GM. Relationship between several surrogate estimates of insulin resistance and quantification of insulin-mediated glucose disposal in 490 healthy nondiabetic volunteers. Diabetes Care. 2000;23:171-5.

24. Nakai $Y$, Nakaishi S, Kishimoto $H$, Seino $Y$, Nagasaka S, Sakai M, et al. The threshold value for insulin resistance on homeostasis model assessment of insulin sensitivity. Diabet Med. 2002;19:346-7.

25. Ateia S, Rusu E, Cristescu V, Enache G, Cheta DM, Radulian G, et al. Proinsulin and age in general population. J Med Life. 2013;6:424-9.

26. Cuartero BG, Lacalle CG, Lobo CJ, Rey CC, Villar MJA. The HOMA and QUICKI indexes, and insulin and C-peptide levels in healthy children. Cut-off points to identify metabolic syndrome in healthy children. An Pediatrics. 2007;66:481-90.

27. Cheal KL, Abbasi F, Lamendola C, McLaughlin T, Reaven GM, Ford ES. Relationship to insulin resistance of the adult treatment panel III diagnostic criteria for identification of the metabolic syndrome. Diabetes. 2004;53:1995-200.

28. Carr DB, Utzshneider KM, Hull RL, Kodama K, Retzlaff BM, Brunzell $\mathrm{JD}$, et al. Intra-abdominal fat is a major determinant of the National 
Cholesterol Education Program Adult Treatment Panel III criteria for the metabolic syndrome. Diabetes. 2004;53:2087-94.

29. Ascott-Evans $\mathrm{BH}$. The metabolic syndrome, insulin resistance and cardiovascular disease. SADJ. 2005;60:122-7.

30. Hanley AJ, Karter AJ, Festa A, D'Agostino RJR, Wagenknecht LE, Savage $P$, et al. Factor analysis of metabolic syndrome using directly measured insulin sensitivity: the Insulin Resistance Atherosclerosis study. Diabetes. 2002;51:2642-7.

31. Sattar N, Preiss D, Murray HM, Welsh P, Buckley BM, de Craen AJ, et al. Statins and risk of incident diabetes: a collaborative meta-analysis of randomized statin trials. Lancet. 2010;375:735-42.

32. Preiss D, Seshasai SR, Welsh P, Murphy SA, Ho JE, Waters DD, et al. Risk of incident diabetes with intensive-dose compared with moderatedose statin therapy: a meta-analysis. JAMA. 2011;305:2556-64.

33. Ray K. Statin diabetogenicity: guidance for clinicians. Cardiovasc Diabet. 2013;12:S3.

34. Mojiminiyi OA, Abdella NA. Effect of homeostasis model assessment computational method on the definition and associations of insulin resistance. Clin Chem Lab Med. 2010;48:1629-34. 


\section{Optimal Cut-Off Value for Homeostasis Model Assessment (Homa) Index of Insulin-Resistance in a Population of Patients Admitted Electively in a Portuguese Cardiology Ward}

Publicado pela Acta Médica Portuguesa, a Revista Científica da Ordem dos Médicos

Av. Almirante Gago Coutinho, 151

1749-084 Lisboa, Portugal.

Tel: +351218428 215

E-mail: submissao@actamedicaportuguesa.com

www.actamedicaportuguesa.com

ISSN:0870-399X | e-ISSN: 1646-0758

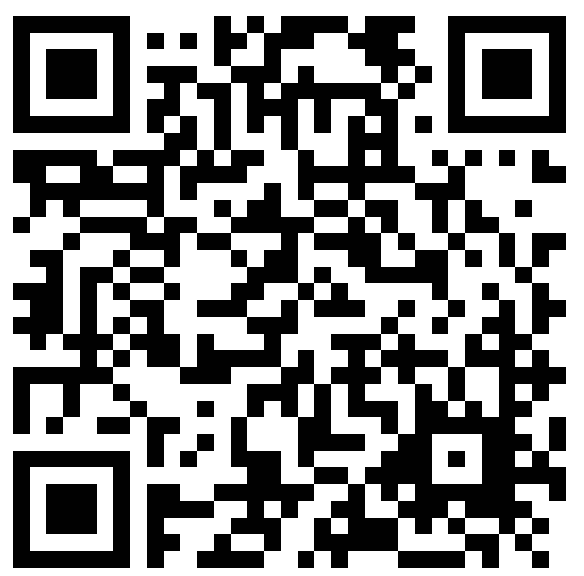

